\title{
Predictors of quality of medication prescribing in primary care in Riyadh city, Saudi Arabia
}

\author{
Y. Neyaz, ${ }^{1}$ T. Khoja, ${ }^{2}$ N.A. Qureshi, ${ }^{3}$ M.A. Magzoub, ${ }^{4}$ A. Haycox ${ }^{5}$ and T. Walley ${ }^{6}$
}

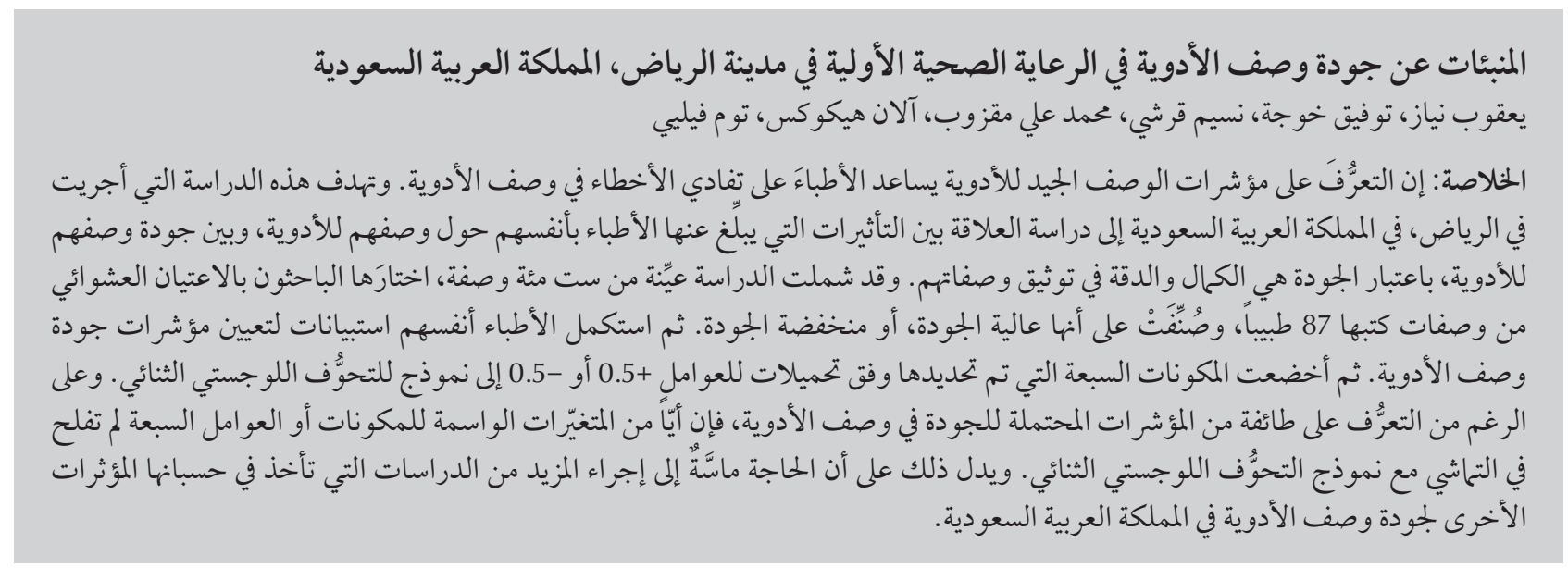

ABSTRACT Identifying the indicators of good quality medication prescribing assists physicians in preventing medication errors. This study in Riyadh city aimed to examine the relationship between physicians' self-reported influences on prescribing and the quality of their prescribing, defined as the completeness and accuracy of their prescription documentation. A sample of 600 randomly selected prescriptions written by 87 physicians were rated as high or low quality. The same physicians completed a questionnaire to determine the indicators of quality prescribing. The 7 components identified with factor loadings +0.5 or -0.5 were subjected to binary logistic regression modelling. While a range of potential quality indicators of drug prescribing were identified, none of the variables underpinning the 7 components/factors survived the binary logistic regression mode. More studies are needed that take into account other quality indicators of medication prescribing in Saudi Arabia.

\section{Facteurs prédictifs d'une prescription de médicament de qualité en soins de santé primaires à Riyadh (Arabie saoudite)}

RÉSUMÉ L'identification des indicateurs relatifs à une prescription de médicament de qualité permet aux médecins d'éviter des erreurs médicamenteuses. La présente étude, réalisée dans la ville de Riyadh, a examiné la relation entre les influences rapportées par les médecins sur leur prescription et la qualité de cette dernière, définie par la complétude et l'exactitude des documents de prescription. Au total, 600 prescriptions rédigées par 87 médecins et sélectionnées par échantillonnage aléatoire ont été évaluées comme étant de bonne ou mauvaise qualité. Les mêmes médecins ont rempli un questionnaire permettant de déterminer les indicateurs d'une prescription de qualité. Les sept composantes identifiées, ayant des saturations de $+0,5$ ou $-0,5$, ont été soumises à un modèle de régression logistique binaire. Si une série d'indicateurs potentiels d'une prescription de médicament de qualité a été identifiée, aucun de ces variables sous-tendant les sept composantes/facteurs n'a passé le test de la régression logistique binaire. Des études supplémentaires sont nécessaires pour prendre en compte d'autres indicateurs d'une prescription de médicament de qualité en Arabie saoudite.

${ }^{1}$ General Directorate for Quality Development; ${ }^{3}$ General Administration for Mental Health and Social Services and Medical Research, Ministry of Health, Riyadh, Saudi Arabia (Correspondence to N.A. Qureshi: qureshinaseem@live.com).

${ }^{2}$ Cooperation Council for the Arab States of the Gulf, Riyadh, Saudi Arabia.

${ }^{4}$ Department of Medical Education, College of Medicine, King Abdulaziz Medical City, Riyadh, Saudi Arabia.

${ }^{5}$ School of Management; ${ }^{6}$ Department of Internal Medicine, University of Liverpool, Liverpool, United Kingdom. 


\section{Introduction}

The writing of correct, precise prescriptions by physicians is an art learned though long practice and training. It is governed by an array of factors, including the physician, the practice setting and the health delivery system $[1-5]$.

Indicators of good quality prescribing that can be measured from simply reading prescriptions include factors such whether the prescription form is completed legibly with all the correct details, e.g. patient's name and age or the dose, frequency and duration of the medication [6]. Others indicators are more difficult to measure: for instance, whether the doctor made a correct diagnosis and prescribed appropriately. This can usually be determined from a review of the patients' notes or, in Saudi Arabia, from the patient management forms which include the diagnosis. The potential weakness of this is that there is no objective verification of the doctors' diagnosis. Another aspect of appropriate prescribing, still more difficult to measure, is whether the doctor had discussed with the patient the potential benefits and risks of the drugs being prescribed, as well as how to use the drug $[3,7-11]$.

This study aimed to examine the relationship between physicians' selfreported influences on prescribing, as identified in a previous study [12], and the quality of their prescribing, defined as the completeness and accuracy of their prescription documentation.

\section{Methods}

The study was a cross-sectional survey of the quality of prescriptions written by physicians from public and private primary health care (PHC) centres in Riyadh and the influences on selfreported prescribing behaviour of the same physicians using data from an anonymous questionnaire.

\section{Sample and setting}

The study setting and sample have been described in earlier papers $[13,14]$. The subjects of the study were 87 PHC physicians (47 in the public sector and 40 in the private sector) from 10 health centres ( 5 in the public sector and 5 in the private sector). In the previous study 2382 prescriptions written by these physicians (1182 from public and 1200 from private PHC centres) were analysed [12]. For the study reported here a sub-sample of $25 \%$ (600 prescriptions) equally distributed among the physicians were randomly selected for further analysis, i.e. an average of 7 prescriptions from each doctor.

\section{Data collection}

Influences on the quality of physicians' prescribing

Aself-administered questionnaire about influences on the quality of their prescribing was completed by the $87 \mathrm{PHC}$ physicians. The items covered training; experience and working environment; methods for updating medical knowledge; sources of prescribing guidance; training in drug prescribing; methods of enhancing knowledge about prescribing; and self-perceived influences on prescribing behaviour. A factor analysis of 56 variables extracted 7 factors that explained $46 \%$ of the variance. The methods have been described in more detail an earlier paper [12].

\section{Prescription quality scores}

To assess prescription quality, the adequacy of each information item on prescriptions written by the same physicians was scored by the principal investigator (Y.N.) as follows (some items were considered of more clinical importance than others and were weighted accordingly): patient's age ( 2 points), file number, date, patient's nationality and sex (1 point each), diagnosis ( 2 points), drug name, dose, duration and frequency ( 2 points), name and signature of prescribing doctor (1 point each) and prescription legible (2 points). The inadequacy of information items was scores with negative scores: inadequate information ( -2 points), diagnosis not recorded ( -2 points), drug variables missing ( -2 points), name and signature of doctor missing (-1 point), prescription illegible ( -2 points) and absence of file number, date, patient nationality and $\operatorname{sex}(-1$ point each). The quality score of each prescription could therefore range from -14 to +14 .

To assess legibility, 3 evaluators (Y.N. and 2 pharmacists) reached a consensus about whether the prescription was clearly written. The diagnosis noted on the prescription was assumed to be the final and correct diagnosis because no data were available to confirm or refute this on the prescription. The score of 2 was kept constant even if there was more than 1 drug prescribed on the prescription by weighting the drugs equally, i.e. if 2 drugs were noted correctly a score of 1 was assigned to each drug, thus scoring 2 for such prescriptions.

A prescription quality score was calculated for each doctor as the mean of these scores, and the physicians were divided into 2 arbitrary categories based on the quality score of the prescriptions they wrote: high (score $\geq 10)$ and low (score $<10$ ).

\section{Data analysis}

The data were entered in the computer using SPSS software, version 10. Analysis was conducted following data cleaning and quality testing. Frequencies were computed for all variables. The statistical procedures used in this study are described in greater detail in the previous study of the determinants of medication prescribing in which factor analysis revealed 7 factors with +0.5 (or more) or -0.5 loadings [12]. These factors were used in a binary logistic regression model to determine causal mechanisms underlying high or low quality prescriptions written by the physicians. The mean prescription quality scores of physicians were considered 


\begin{tabular}{llcc}
\hline $\begin{array}{l}\text { Table 1 Summary of items clustering in the } 7 \text { factors and the factor loadings } \\
\text { Variable }\end{array}$ & \multicolumn{1}{c}{ Summary of cluster items } & Score & $\boldsymbol{P}_{\text {-value }}$ \\
Factor 1 & Size and organization of health centre & 0.166 & 0.684 \\
Factor 2 & Scepticism about the value of meetings & 0.204 & 0.652 \\
Factor 3 & Physician age and experience & 0.308 & 0.579 \\
Factor 4 & Access to information & 0.160 & 0.689 \\
Factor 5 & Attendance at meetings & 0.359 & 0.549 \\
Factor 6 & Consultation and organizational elements & 0.026 & 0.872 \\
Factor 7 & Physician nationality and educational factors & 0.490 & 0.484 \\
Overall & & 1.215 & 0.991 \\
\hline
\end{tabular}

as the dependent variable and the 7 prescribing influences variables were considered as the independent variables, and hence possible predictors of quality of prescriptions.

\section{Results}

\section{Physicians' prescription quality scores}

The prescription quality scores of the whole group of 87 physicians ranged from +3 to +12 . Using the cut-off score of 10, 64 PHC physicians (72\%) were classified as writing low quality prescriptions. The prescription quality scores of the low quality prescribes ranged from +3 to +9 and the mean for this group was +7.5 (SD 1.6). The remaining PHC physicians $(n=23,28 \%)$ were classified as writing high quality prescriptions; their quality scores ranged from +10 to +12 and the mean for the group was +10.8 (SD 1.6).

\section{Physicians' self-reported influences on prescribing}

The descriptive statistics and frequency distribution of the variables relating to physicians' self-reported influences on prescribing have been presented before [12]. When these variables were factor analysed using varimax rotation, 7 factors were defined by the linear combination of heavy loads ( +0.5 and -0.5$)$. Items combined in factor 1 appeared to relate to the positive impact of the size and organization of the health centre. Factor 2 appeared to scepticism about the value of meetings in altering prescribing behaviour. Factor 3 combined items relating to the physician's age and experience. Factor 4 combined items relating to access to information. Factor 5 largely related to attendance at meetings and training. Factor 6 combined items relating to consultation and organizational elements. Finally, factor 7 combined 2 apparently unrelated items relating to the physician's nationality and educational factors.

\section{Relationship of physicians' prescription quality scores to self-reported influences on prescribing}

In the present study these factors/ components were used to predict the quality of drug prescriptions defined by the physicians' prescribing quality score using a binary logistic modelling technique. However, none of the variables underpinning the 7 components/ factors survived the binary logistic regression model $(P>0.05)$ (Table 1$)$.

\section{Discussion}

This study utilized physicians' responses to a questionnaire designed to determine influences on drug prescribing behaviour in order to identify the predictors of prescription quality. According to this study, none of the variables related to physicians, patients or health care delivery settings were found to significantly influence prescription quality. We therefore conclude that the determinants of drug prescribing included in this questionnaire had no direct relevance to quality indicators of drug prescriptions. There may be several explanations for this: first, the measure of quality of prescribing used here was generated only for this study and has not been validated elsewhere. More time spent developing this measure could have been useful, although it is difficult to envision what other measures reflecting quality could be derived simply from reading prescriptions. This point was made by Marinker and Reilly, who argued that examining prescribing alone - the end product of the whole consultation-diagnostic-therapeutic pathway - is inadequate as a measure of quality of care [15]. It may be that doctors do not view the need for good quality record-keeping and the physical act of writing the prescription as important factors. Intuitively, however, poor prescription writing raises questions abut the quality of other aspects of the consultation

Secondly, the sample size was relativelysmall: 87 doctors and 600 prescriptions, i.e. only around 7 prescriptions per doctor, and a large number of variables were obtained from the questionnaire. Studies evaluating prescribing in the UK have been able to use much larger numbers because of the recording of prescribing through the computerized prescribing analyses and cost (PACT) system [16]. Even so, according to one study, only certain PACT-based indicators could viewed as measures of 
quality, and consensus about the validity of PACT-based indicators was low: 5 of 41 were judged to be valid for quality and 7 for cost minimization [17]. Such a comprehensive computer-based system of recording prescribing behaviour does not exist in Saudi Arabia or other Gulf states. The doctors in the public sector are prescribing from within a very constrained public formulary, and overall costs are controlled largely by drug selection for the formulary.

Thirdly, the questionnaire may have attracted only normative responses, e.g. most doctors claimed to fill in the patient management form comprehensively although the evidence of the prescriptions written and examined here suggested that this was the case only for one-third of the doctors. It seems unlikely that the doctors were truly unaware of their poor prescribing behaviour, so it may have been that they feared retribution or sanctions if their questionnaire suggested unsatisfactory behaviour. This was despite assurances of protection of their anonymity and that the work was being undertaken as academic research and not as a managerial exercise, and may reflect their lack of awareness of the nature of research in a research naive environment. The doctors were in theory aware that the researcher had access to their prescriptions but that permission to look at these had come from the Ministry of Health and they may have been suspicious about the implications of further data collection. It seems, however, that they were unaware that the researcher might compare their written prescriptions with their answers to the questionnaire.

Nevertheless the results of this research do highlight the issue of prescribing quality in Saudi Arabia. Almost three-quarters of $\mathrm{PHC}$ physicians in this study (72\%) were classified as writing low quality prescriptions. Doctors need to see prescribing as a professional and not just as a managerial activity or else professional commitment is likely to be limited. Managers have a duty to ensure quality in any public service, so the use of some form of summary statistics of quality prescribing may be needed. These will require careful development in Saudi Arabia. There are many attempts to derive such statistics in relation to prescribing, e.g. in the UK and by the World Health Organization. A computer search of relevant literature revealed a range of prescribing quality indicators $[3,17,18-22]$ which commonly include the rate of generic prescribing, e.g. prescriptions for generic antibiotics as a percentage of all antibiotics prescribed, and the ratio of one drug to another drug and its main pharmacological group, e.g. prescriptions for atenolol and propranolol as a percentage of beta-blockers prescribed.
We can identify some limitations and areas for further research. The quality and interpretation of factor analysis was entirely dependent upon the perceived integrity and robustness of the factor combinations. As such, our analysis should be regarded as presenting an initial exploration of this complex area of study. The scoring system of prescriptions might be perceived as being somewhat arbitrary. Certainly, further research into the impact of such scoring systems on the overall results obtained would provide valuable evidence on the robustness of the underlying results. In this analysis, we did not check the validity of this scoring system, but its face validity seemed to be good. A second potential weakness is the extent to which the physicians randomly included in this study were representative of Saudi physicians as a whole. The sample was taken from large health centres in Riyadh, and the generalizability of the results to smaller health centres outside the capital is open to question. Finally, the statistical analysis underpinning the study was based on binary logistic regression. Such an approach, combined with the comparatively small sample size, made it difficult to reveal any good/bad quality indicators of drug prescriptions. Therefore, another potential extension of this research would be to utilize additional relevant statistical procedures to more effectively isolate quality indicators of prescriptions.

\section{References}

1. Ellis $R$, Whittington $\mathrm{D}$, eds. Quality assurance in health care: $a$ handbook. London, Edward Arnold, 1994.

2. Scott A, Smith RD. Keeping the customer satisfied: issues in the interpretation and use of patient satisfaction surveys. International Journal for Quality in Health Care, 1994, 6:353-359.

3. Report of the WHO working group on quality assurance. Geneva, World Health Organization, 1994:18-20.

4. Helin-Samivaara A et al. Focus on changing clinical practice to enhance rational prescribing-collaboration and networking enable comprehensive approaches. Health Policy, 2003, 66:1-10.

5. Effken JA et al. Using OrgAhead, a computational modeling program, to improve patient care unit safety and quality outcomes. International Journal of Medical Informatics, 2005, 74:605-613.

6. Williams D, Bennett K, Feely J. The application of prescribing indicators to a primary care prescription database in Ireland. European Journal of Clinical Pharmacology, 2005, 61:127-133.

7. Awé C, Lin SJ. A patient empowerment model to prevent medication errors. Journal of Medical Systems, 2003, 27:503-517.

8. Davies HTO, Crombie IK. Assessing the quality of care. British Medical Journal, 1995, 311:766.

9. Grube JA. Learning from health care errors: effective reporting systems. Journal for Healthcare Quality, 2001, 23:25-29.

10. Hatlie MJ, Wilson NJ. Advancing patient safety: a framework for accountability and practical action. Journal for Healthcare Quality, 2001, 23:30-34. 
11. Johnell $\mathrm{K}$ et al. Individual characteristics, area social participation, and primary non-concordance with medication: a multilevel analysis. BMC Public Health, 2006, 6:52.

12. Magzoub MA et al. Determinants of physicians' medication prescribing behaviour in primary care in Riyadh city, Saudi Arabia. Eastern Mediterranean Health Journal, 2011(2):160-166.

13. Neyaz Y et al. Medication prescribing pattern in primary care in Riyadh city, Saudi Arabia. Eastern Mediterranean Health Journal, 2011(2):149-155.

14. Khoja T et al. Medication errors in primary care in Riyadh city, Saudi Arabia. Eastern Mediterranean Health Journal, 2011(2):156-159.

15. Marinker M, Reilly P. Rational prescribing: How can it be judged? Controversies in health care policies: challenges to practice. London, British Medical Journal Publishing Group, 1994:89-110.

16. Wilson RP et al. Influences of practice characteristics on prescribing in fundholding and non-fundholding general practices: an observational study. British Medical Journal, 1996, 313:595-599.
17. Campbell SM, Cantrill JA, Roberts D. Prescribing indicators for UK general practice: Delphi consultation study. British Medical Journal, 2000, 321:425-428.

18. Queenborough R, Roberts D. The relationship between the quality of prescribing indicators and their availability: a model for primary care groups. Prescriber, 1999, 10:47-51.

19. Chapman S, Durieux P, Walley T. Good prescribing practice. In: Mossialos E, Mrazek M, Walley T, eds. Regulating pharmaceuticals in Europe: striving for efficiency, equity and quality. Milton Keynes, UK, Open University Press, 2004.

20. Freemantle $\mathrm{N}$ et al. A randomised controlled trial of the effect of educational outreach by community pharmacists on prescribing in UK general practice. British Journal of General Practice, 2002, 52:290-295.

21. Freemantle $\mathrm{N}$ et al. Printed educational materials: effects on professional practice and health care outcomes. Cochrane Database of Systematic Reviews, 2000, 2.

22. Majeed A, Evans N, Head P. What can PACT tell us about prescribing in general practice? British Medical Journal, 1994, 315:1515-1519.

\section{WHO Statistical Information System (WHOSIS)}

\section{World Health Statistics report}

World Health Statistics 2010 contains WHO's annual compilation of data from its 193 Member States, and includes a summary of progress towards the health-related Millennium Development Goals and targets.

The report for 2010 is now available. for download in Adobe PDF and excel when applicable. The report is published in 6 languages including Arabic, English, and French, and can be accessed from:

http://www.who.int/whosis/whostat/en/index.html 